\title{
Atividade clastogênica e genotóxica de altas concentrações do extrato aquoso de Agaricus brasiliensis e diferentes respostas quando associado aos inibidores de reparo de DNA, ARA-C e 3DEOT, in vitro.
}

\section{Clastogenic and genotoxic activity of high concentrations of Agaricus brasiliensis aqueous extract and different responses when associated to ARA-C and 3deot DNA repair inhibitors, in vitro.}

\author{
M. S. Mantovani ${ }^{1}$; R. Matuo ${ }^{1}$; M.F. Bellini ${ }^{1}$; R.J. Oliveira ${ }^{1}$; L.R. Ribeiro ${ }^{2}$
}

\section{Resumo}

\begin{abstract}
O Agaricus brasiliensis Wasser \& Didukh - Ab (=Agaricus blazei Murrill ss. Heinemann) é um basidiomiceto que vem sendo consumido em diversas partes do mundo no combate e tratamento de muitas doenças. Neste estudo, foram testados, em células de ovário de hamster chinês (CHO-k1), os efeitos clastogênicos e genotóxicos de altas concentrações de $\mathrm{Ab}$ e seu potencial protetor, por meio dos ensaios de aberração cromossômica (AC) e cometa (SCGE), associados a dois bloqueadores de reparo do DNA (citosina arabinoside trifosfato - Ara-C - inibidor de DNA polimerase $\alpha$ e 3'deoxitimidina 5 'trifosfato - 3DeoT - inibidor de DNA polimerase $\beta$ ), na presença ou não de um agente alquilante (metilmetanosulfonato). No teste de clastogenicidade, verificou-se que as concentrações 0,2 e $0,4 \%$ não se mostraram indutoras de dano, ao contrário da maior concentração $(0,6 \%)$. Nos tratamentos de genotoxicidade no SCGE, a concentração de $0,2 \%$ do extrato não mostrou atividade genotóxica, ao contrário das concentrações de 0,4 e $0,6 \%$, as quais foram efetivas indutoras de danos no DNA. Os resultados de anticlastogenicidade indicaram que, na maioria dos tratamentos realizados, o extrato aquoso de Ab não apresentou atividade protetora contra danos no DNA, induzidos pela Ara-C e Ara-C + MMS. Pelo SCGE, Ab, nas três concentrações testadas, não mostrou atividade antigenotóxica. Os dados sugerem cuidado no consumo e ingestão de $\mathrm{Ab}$ por seres humanos, principalmente em altas concentrações.
\end{abstract}

Palavras-chave: Agaricus brasiliensis. Aberração Cromossômica. Ensaio do Cometa. Reparo de DNA.

\begin{abstract}
The Agaricus brasiliensis Wasser \& Didukh - Ab (=Agaricus blazei Murrill ss. Heinemann) is a basidiomycete that has been world wide consumed on the fight and treatment of several diseases. In this study, ovary cells (CHO-k1) in Chinese hamster, the clastogenic and genotoxic effects of Ab high concentrations and its protector potential, were tested, through the chromosome aberration (AC) and comet assays (SCGE), associated to two DNA repair blockers (cytosine arabinoside triphosphate - AraC, DNA polymerase $\alpha$ inhibitor and 3' deoxithymidine 5' triphosphate - 3DeoT, DNA polymerase $\beta$
\end{abstract}

\footnotetext{
${ }^{1}$ Depto de Biologia Geral, Universidade Estadual de Londrina - Londrina, PR. E-Mail: biomsm@uel.br

${ }^{2}$ Depto de Patologia, UNESP - Botucatu, SP.
} 
inhibitor) at the presence or not of an alkylant agent (methylmethanesulfonate - MMS). In the clastogenicity test, it was verified that the 0.2 and $0.4 \%$ concentrations did not seem to be damage inducers, unlike the higher concentration one ( $0.6 \%$ ). On the genotoxicity treatments in SCGE, the $0.2 \%$ concentration did not show genotoxic activity, unlike the 0.4 and $0.6 \%$ concentrations, which were effective DNA damage inducers. The anticlastogenicity results indicate that, on most of the performed treatments, the $\mathrm{Ab}$ aqueous extract did not show protective activity against DNA damages induced by Ara-C and Ara-C + MMS. Through the SCGE, Ab, at the three tested concentrations, it did not show antigenotoxic activity. The data suggest precaution on the consumption and ingestion of $\mathrm{Ab}$ by human beings, especially at high concentrations.

Key words: Agaricus brasiliensis. Chromosome aberration. Comet Assay. DNA repair.

\section{Introdução}

Muitos compostos naturais têm sido estudados a fim de se conhecer suas propriedades antimutagênicas, e incluí-los na dieta humana, com intuito de prevenir ou auxiliar no tratamento de doenças. Entre eles, cita-se o basidiomiceto Agaricus brasiliensis (WASSER et al., 2002), classificado anteriormente como Agaricus blazei Murrill ss. Heinemann, nativo do Brasil. Esse basidiomiceto vem sendo administrado na medicina popular em diferentes formas, principalmente como chá, e é indicado para combater o estresse físico e emocional, e para o tratamento e prevenção de doenças como diabetes, osteoporose e úlcera gástrica, problemas digestivos e circulatórios, e para reduzir o colesterol, como estimulante do sistema imunológico. Além disso, ele tambémé usado como antioxidante e anticarcinogênico (MIZUNO, 1995).

O corpo de frutificação do Ab consiste em 85 a $87 \%$ de água. Quando desidratado, é rico em proteínas (40 a 45\%), carboidratos (3 a 4\%), fibras (6 a 8\%), resíduos totais (5 a 7\%), lipídeos (3 a $4 \%)$ e vitaminas como: $\mathrm{B}_{1}(0,3 \mathrm{mg} \%), \mathrm{B}_{2}(3,2 \mathrm{mg} \%)$ e miacina $(49,2 \mathrm{mg} \%)$. Contém uma quantidade relativamente grande de ergosterol $(0,1$ a $0,2 \%)$, o qual é convertido em vitamina $\mathrm{D}_{2}$, via pré-vitamina $\mathrm{D}_{2}$, após a exposição à luz e ao cozimento. $\mathrm{O}$ principal componente mineral de Ab é o potássio (2,97\%) (MIZUNO, 1995).

A partir dos resíduos do corpo de frutificação de Ab, solúveis em água, um complexo protéico,

(1" 6)-p-D-glucana, foi isolado com 50,2\% de carboidrato e $43,3 \%$ de proteína. A análise dos aminoácidos desse complexo mostraram grandes quantidades de alanina $(11,9 \%)$ e tirosina $(2,4 \%)$
(KAWAGISHI et al., 1989; KAWAGISHI et al., 1990). Esse complexo proteína-polissacarídeo foi caracterizado pela inibição de sarcoma-180 em camundongos, desenvolvendo propriedade imunomoduladora (ITOH; AMANO; NODA, 1994), possibilitando mecanismos imunológicos envolvidos na ação de várias células imunocompetentes (ITO; NAKAMURA, 1997; EBINA; FUJIMIYA, 1998; FUJIMIYA et al., 1999).

Atualmente, há um crescente interesse científico em estudar os efeitos antitumorais e antimutagênicos de $\mathrm{Ab}$ no sentido de obter evidências a favor de seu efeito protetor contra danos ao DNA e de encontrar mais uma fonte de substâncias antimutagênicas. Neste trabalho foram investigados os efeitos clastogênico e/ou anticlastogênico e os efeitos genotóxico e/ou antigenotóxico de extratos aquosos de Ab em cultura de células de ovário de hamster chinês, CHO-k1, através dos ensaios de aberrações cromossômicas (AC) e cometa (SCGE), com inibição do mecanismo de reparo de danos do DNA. Foram avaliados os efeitos protetores de dois extratos aquosos preparados de formas diferentes, um preparado de forma semelhante ao uso do $\mathrm{Ab}$ pela população e outro preparado quimicamente (após a extração de compostos orgânicos).

\section{Materiais e Métodos}

\section{Linhagem celular e condições de cultura}

Nesse estudo foram utilizadas células de ovário de hamster chinês, CHO-k1, fornecidas pelo 
Atividade clastogênica e genotóxica de altas concentrações do extrato aquoso de Agaricus brasiliensis e diferentes respostas quando associado aos inibidores de reparo de DNA, Ara-C e 3Deo T, in vitro.

Laboratório de Mutagênese da Faculdade de Medicina de Ribeirão Preto, Universidade de São Paulo. As células foram cultivadas como monocamada em frascos de $25 \mathrm{~cm}^{2}$. Para o cultivo celular, foi utilizado meio de cultura F-12/DMEM (Gibco), suplementado com $10 \%$ de soro bovino fetal (Gibco), em estufa do tipo BOD a $37^{\circ} \mathrm{C}$. Nessas condições, o tempo de ciclo celular é de aproximadamente $12 \mathrm{~h}$.

\section{Agentes químicos}

A citosina arabinoside trifosfato - Ara-C - foi dissolvida em dimetilsufóxido - DMSO (Mallinckrodt) e diluída em tampão fosfato PBS, livre de $\mathrm{Ca}^{+2} \mathrm{e} \mathrm{Mg}^{+2}$, utilizada na concentração final de $0,25 \mu \mathrm{g} / \mathrm{mL}$ no ensaio de aberrações cromossômicas e $0,125 \mu \mathrm{g} / \mathrm{mL}$ no ensaio do cometa. A 3'Deoxitimidina 5' Trifosfato - 3DeoT - foi dissolvida em DMSO e diluída em PBS, utilizada na concentração final de $0,5 \mu \mathrm{g} / \mathrm{mL}$ no ensaio de aberrações cromossômicas e $0,25 \mu \mathrm{g} / \mathrm{mL}$ no ensaio do cometa. O etilmetanosulfonato - EMS - e o metilmetanosulfonato-MMS - foram diluídos em PBS e utilizados nas concentrações finais em cultura de $155 \mu \mathrm{g} / \mathrm{mL}$ e $2 \times 10^{-4} \mathrm{M}$, respectivamente.

\section{Extratos de Agaricus brasiliensis Wasser \& Didukh}

Foram testados dois tipos de extratos aquosos de $\mathrm{Ab}$. O primeiro e mais comum deles foi preparado na concentração $10 \%$, dissolvendo $20 \mathrm{~g}$ do cogumelo desidratado e moído em $200 \mathrm{~mL}$ de água deionizada a temperatura ambiente $\left(20^{\circ} \mathrm{C}\right)$. Vale ressaltar que a concentração recomendada para o uso pela população é de $2,5 \%$, ou seja, $5 \mathrm{~g}$ em $200 \mathrm{~mL}$. O preparado foi filtrado em papel de filtro, e em seguida, esterilizado em membrana de éster celulose, com $0,22 \mu \mathrm{m}$ de poro. Foram utilizadas três concentrações desse extrato: 0,2, 0,4 e 0,6\% em cultura. $\mathrm{O} \mathrm{Ab}$ foi fornecido pelo Departamento de Produção Vegetal, UNESP- Botucatu- SP, pelo Dr.
Augusto F. da Eira. Esse extrato foi testado nos ensaios do cometa e aberração cromossômica (AC-I).

Posteriormente, um segundo extrato aquoso, produzido após extração de compostos orgânicos, foi fornecido pelo Departamento de Química Universidade Federal de São Carlos - SP, preparado a partir do mesmo cogumelo desidratado e moído, descrito anteriormente. $\mathrm{O}$ extrato foi dissolvido em DMSO na proporção de $5 \mathrm{mg} / \mathrm{ml}$, sendo a concentração final em cultura de $100 \mu \mathrm{g} /$ $\mathrm{mL}$. Este extrato foi utilizado no ensaio de aberração cromossômica (AC-II).

\section{Procedimentos e tratamentos no ensaio de aberração cromossômica}

Foram realizados dois estudos com o teste de aberração cromossômica. No primeiro, (AC-I), investigou-se o potencial anticlastogênico de $\mathrm{Ab}$ perante inibição de reparo de DNA, com ou sem indução de dano por MMS, através dos seguintes tratamentos: (a) Controle; (b) Ab; (c) Ara-C (d) Ara-C + MMS; (e) Ara-C + Ab; (f) Ara-C + MMS + Ab. Os tratamentos foram simultâneos e contínuos durante um ciclo celular.

No segundo, (AC-II), investigou-se o potencial anticlastogênico de $\mathrm{Ab}$ perante inibição de reparo de DNA através de dois diferentes agentes, pelos seguintes tratamentos: (a) Controle; (b) Ab; (c) AraC; (d) 3DeoT; (e) Ara-C + Ab; (f) 3DeoT + Ab. Os tratamentos foram simultâneos e contínuos durante um ciclo celular.

Colcemide (Demecolcine, Sigma) $(0,1 \mu \mathrm{g} / \mathrm{mL})$ foi adicionado às culturas por um período de $90 \mathrm{~min}$ antes do final dos tratamentos. Após o término dos tratamentos, as células foram tripsinizadas $(0,025 \%)$ e posteriormente hipnotizadas em solução de citrato de sódio $(1 \%)$, à $37^{\circ} \mathrm{C}$ por $20 \mathrm{~min}$. As células foram fixadas em metanol/ácido-acético (3:1) e as lâminas foram coradas com Giemsa 5\% por 5 minutos. Três repetições independentes foram realizadas para cada tratamento, em cada teste. 
Foram analisadas 100 metáfases por cultura, num total de 300 células por tratamento. Aberrações cromossômicas foram classificadas como isocromatídicas (ic: quebras isocromatídicas; dic: dicêntrico; r: anel) ou cromatídicas (ct: quebras cromatídicas; tr: trirradial; qr: quadrirradial; rc: rearranjo complexo). Metáfases com mais de 10 aberrações cromossômicas foram classificadas como aberrações múltiplas (ma).

Procedimentos e tratamentos no ensaio do cometa (Single Cell Gel Eletrophoresis - SCGE)

Neste ensaio, foram realizados os seguintes tratamentos: (a) controle; (b) EMS; (b) Ab; (c) AraC; (d) 3DeoT; (e) Ara-C + Ab; (f) 3DeoT + Ab. Todos os tratamentos foram realizados por 3 horas, em meio de cultura livre de soro bovino fetal. Três repetições independentes foram realizadas para cada tratamento. Para realização do ensaio do Cometa, foi utilizado o protocolo de Speit e Hartmann (1999). Após o período de tratamento, as células foram tripsinizadas, centrifugadas e ressuspendidas em meio de cultura. A suspensão celular $(20 \mu \mathrm{L})$ foi misturada à agarose LMP $0,5 \%$ (120 $\mu \mathrm{L}$, low melting point), a $37^{\circ} \mathrm{C}$, e distribuída sobre lâminas de microscopia, pré-gelatinizadas com agarose normal 1,5\%. Cobriram-se as lâminas, e estas foram mantidas à $4^{\circ} \mathrm{C}$ por $20 \mathrm{~min}$. Após, removeu-se as lamínulas e as lâminas foram imersas em solução de lise $(89,9 \mathrm{ml}-2.5 \mathrm{M} \mathrm{NaCl}, 100 \mathrm{mM}$ EDTA, 10mM Tris, pH 10; + 1mL Triton X-100 + $10 \mathrm{~mL}$ DMSO), protegidas da luz, à $4^{\circ} \mathrm{C}$ por $1 \mathrm{~h}$. Após a lise, as lâminas foram levadas para cuba eletroforética, imersas em tampão $(300 \mathrm{mM} \mathrm{NaOH}$ por 1mM EDTA, preparados a partir de uma solução estoque de $\mathrm{NaOH} 10 \mathrm{~N}$ e EDTA $200 \mathrm{mM}$, $\mathrm{pH} 10,0), \mathrm{pH}>13$, à $4^{\circ} \mathrm{C}$ por $20 \mathrm{~min}$ para desnaturação.

A eletroforese ocorreu à $4^{\circ} \mathrm{C}$ por $20 \mathrm{~min}$, à $25 \mathrm{~V}$ e $300 \mathrm{~mA}(1,6 \mathrm{~V} / \mathrm{cm})$. Após eletroforese, as lâminas foram neutralizadas com tampão $(0,4 \mathrm{M}$ Tris-HCl) por $15 \mathrm{~min}$ ( 3 ciclos de $5 \mathrm{~min}$ ), secas e fixadas em álcool etílico $100 \%$ por $10 \mathrm{~min}$., e armazenadas até análise. No momento da leitura, as lâminas foram coradas com $100 \mu \mathrm{L}$ de brometo de etídio, $200 \mu \mathrm{g} /$ $\mathrm{mL}$, e cobertas com lamínulas. O material foi analisado em microscópio de fluorescência em objetiva de 40X, com filtro de excitação de 420$490 \mathrm{~nm}$ e filtro de barreira de $520 \mathrm{~nm}$. Foram analisadas 100 células (KOBAYASHI et al., 1995) por tratamento, em cada repetição, classificandoas em classes: (classe 0) ausência de cauda; (classe 1) cauda com até o diâmetro da cabeça do cometa; (classe 2) cauda de tamanho médio, com 2 vezes o diâmetro da cabeça; (classe 3) cauda longa, com comprimento superior a 2 vezes o diâmetro da cabeça. Células apoptóticas que apresentavam núcleo totalmente fragmentado não foram contabilizadas.

\section{Análise estatística}

As análises estatísticas dos ensaios de aberrações cromossômicas foram feitas empregando o teste estatístico do $\chi^{2}$. A análise do ensaio do cometa foi feita empregando ANOVA, pelo teste de Tukey.

\section{Resultados}

\section{Ensaio de aberração cromossômica}

A avaliação da clastogenicidade e/ou anticlastogenicidade do extrato aquoso de $\mathrm{Ab}$ foi realizada em células de ovário de hamster chinês, CHO-k1, perante inibição do mecanismo de reparo de DNA, associada ou não a agente indutor de danos MMS.

A Tabela 1 mostra o número total de células com aberrações cromossômicas obtido nos testes de clastogenicidade e anticlastogenicidade (ACI) dos extratos de $\mathrm{Ab}$, em três concentrações, associado ao Ara-C, e ao Ara-C + MMS. Pela análise desta tabela, verifica-se que as concentrações 

quando associado aos inibidores de reparo de DNA, Ara-C e 3Deo T, in vitro.

do extrato aquoso 0,2 e $0,4 \%$ não apresentaram atividade clastogênica significativa, ao contrário da maior concentração, $0,6 \%$. Observa-se que, na maioria dos tratamentos de anticlastogenicidade, não houve diferença significativa para os valores encontrados associado ao Ara-C, e ao Ara-C +
MMS, exceto no tratamento associando o $\mathrm{Ab} 0,6 \%$ ao Ara-C + MMS, que mostrou atividade protetora significativa do cogumelo. A porcentagem de redução de aberrações cromossômicas, nos testes de anticlastogenicidade, variou de 2,63 a 47,36\%.

Tabela 1. Freqüências de aberrações cromossômicas encontradas nos tratamentos com extrato aquoso de $\mathrm{Ab}$, associado ao Ara-C, e ao Ara-C + MMS, in vitro (AC-I).

\begin{tabular}{|c|c|c|c|}
\hline \multirow{2}{*}{ Tratamentos } & \multicolumn{2}{|c|}{$\mathrm{N}^{0}$ células com aberrações } & \multirow{2}{*}{ \% redução } \\
\hline & Total $^{1}$ & $\%$ & \\
\hline Controle & 4 & 1,3 & \\
\hline \multicolumn{4}{|l|}{ Clastogenicidade } \\
\hline Ab $0,2 \%$ & 5 & 1,7 & - \\
\hline Ab $0,4 \%$ & $10^{\mathrm{a}}$ & 3,3 & - \\
\hline Ab 0,6\% & $21^{\mathrm{a} *}$ & 7,0 & - \\
\hline \multicolumn{4}{|c|}{ Anticlastogenicidade (Inibição Reparo) } \\
\hline Ara-C & $38^{\mathrm{a} *}$ & 12,7 & - \\
\hline Ara-C $+A b 0,2 \%$ & $28^{\mathrm{b}}$ & 9,3 & 35,7 \\
\hline Ara-C + Ab 0,4\% & $33^{\mathrm{b}}$ & 11,0 & 17,8 \\
\hline Ara-C $+A b 0,6 \%$ & $33^{\mathrm{b}}$ & 11,0 & 17,8 \\
\hline \multicolumn{4}{|c|}{ Anticlastogenicidade (Indução de Dano e Inibição de Reparo) } \\
\hline MMS & $35^{\mathrm{a} *}$ & 11,7 & - \\
\hline Ara-C + MMS & $48^{\mathrm{a} *}$ & 16,0 & - \\
\hline Ara-C + MMS + Ab 0,2\% & $47^{\mathrm{c}}$ & 15,7 & 2,63 \\
\hline Ara-C + MMS + Ab 0,4\% & $33^{\mathrm{c}}$ & 11,0 & 39,47 \\
\hline Ara-C + MMS + Ab 0,6\% & $30^{\mathrm{c}} *$ & 10,0 & 47,36 \\
\hline
\end{tabular}

Ab - extrato aquoso de Agaricus brasiliensis; Ara-C - Citosina Arabinoside Trifosfato ( $0,25 \mu \mathrm{g} / \mathrm{mL})$; MMS - metilmetanosulfonato

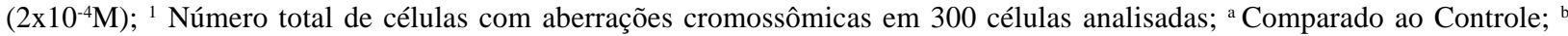

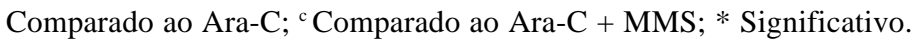

A Tabela 2 mostra os tipos de aberrações cromossômicas encontradas. Verifica-se, por meio desta, que a grande maioria das aberrações é do tipo cromatídica (quebras cromatídicas, trirradiais, quadrirradiais e rearranjos complexos).

Tabela 2. Tipos de aberrações cromossômicas encontradas em culturas CHO-k1 tratadas com extrato aquoso de Ab, associado ao Ara-C e ao Ara-C + MMS (AC-I).

\begin{tabular}{|c|c|c|c|c|c|c|c|c|c|c|}
\hline \multirow{3}{*}{ Tratamentos } & \multicolumn{10}{|c|}{ Número de aberrações cromossômicas } \\
\hline & \multicolumn{10}{|c|}{ Tipos de quebras } \\
\hline & ct & tr & $\mathbf{q r}$ & re & Total $^{1}$ & ic & $\mathbf{r}$ & dic & Total $^{2}$ & am \\
\hline Controle & 8 & 1 & 1 & 1 & 11 & 4 & 0 & 0 & 4 & 0 \\
\hline \multicolumn{11}{|l|}{ Clastogenicidade } \\
\hline Ab $0,2 \%$ & 1 & 0 & 1 & 0 & 2 & 5 & 0 & 0 & 5 & 0 \\
\hline Ab $0,4 \%$ & 7 & 1 & 0 & 0 & 7 & 5 & 0 & 0 & 5 & 0 \\
\hline Ab $0,6 \%$ & 17 & 0 & 0 & 0 & 17 & 6 & 0 & 0 & 6 & 0 \\
\hline \multicolumn{11}{|c|}{ Anticlastogenicidade (Inibição Reparo) } \\
\hline Ara-C & 22 & 1 & 0 & 1 & 24 & 17 & 0 & 1 & 18 & 0 \\
\hline Ara-C+Ab $0,2 \%$ & 27 & 1 & 0 & 0 & 28 & 8 & 0 & 2 & 10 & 0 \\
\hline Ara-C+Ab $0,4 \%$ & 23 & 1 & 0 & 2 & 26 & 9 & 2 & 0 & 11 & 0 \\
\hline Ara-C $+A b 0,6 \%$ & 23 & 2 & 6 & 3 & 34 & 5 & 2 & 1 & 8 & 1 \\
\hline \multicolumn{11}{|c|}{ Anticlastogenicidade (Indução de Dano e Inibição de Reparo) } \\
\hline MMS & 19 & 2 & 4 & 4 & 29 & 7 & 2 & 0 & 9 & 0 \\
\hline Ara-C+MMS & 26 & 3 & 6 & 4 & 39 & 13 & 1 & 0 & 14 & 0 \\
\hline Ara-C+MMS+Ab 0,2\% & 40 & 3 & 6 & 2 & 51 & 1 & 1 & 0 & 2 & 0 \\
\hline Ara-C+MMS+Ab 0,4\% & 15 & 1 & 0 & 3 & 19 & 5 & 0 & 0 & 5 & 0 \\
\hline Ara-C+MMS+Ab $0,6 \%$ & 49 & 1 & 1 & 1 & 52 & 8 & 2 & 0 & 10 & 0 \\
\hline
\end{tabular}

$\mathrm{Ab}$ - extrato aquoso de Agaricus brasiliensis; Ara-C - Citosina Arabinoside Trifosfato ( $0,25 \mu \mathrm{g} / \mathrm{mL})$; MMS - metilmetanosulfonato $\left(2 \times 10^{-4} \mathrm{M}\right) ;{ }^{1}$ Quebras do tipo cromatídicas: ct (quebra cromatídica), tr (trirradial), qr (quadrirradial), rc (rearranjo complexo); ${ }^{2}$ Quebras do tipo isocromatídicas: ic (quebra isocromatídica), $\mathrm{r}$ (anel), dic (dicêntrico); am: aberrações múltiplas. 
A Tabela 3 mostra o número total de células com aberrações cromossômicas obtido no teste de clastogenicidade e anticlastogenicidade (AC-II) do extrato de $\mathrm{Ab}$, associado aos inibidores de reparo de DNA, Ara-C e 3DeoT. A partir dos resultados desta tabela, verifica-se que o extrato aquoso não apresentou efeito clastogênico, visto que, o total de metáfases aberrantes não difere significativamente do controle. Observa-se também que o extrato, na concentração utilizada, não apresentou atividade protetora significativa quando associada ao inibidor de reparo de DNA Ara-C, mas mostrou-se protetor quando associado ao 3DeoT. A porcentagem de redução de aberrações cromossômicas, nos testes de anticlastogenicidade, variou de 25,6 a 65,7\%.

Tabela 3. Anticlastogenicidade do extrato aquoso de Ab, em culturas de CHO-k1 tratadas com inibidores de reparo de DNA (AC-II).

\begin{tabular}{cccc}
\hline & \multicolumn{2}{c}{$\mathbf{N}^{0}$ Células com } \\
Aberrações & Redução (\%) \\
\cline { 2 - 3 } Tratamentos & Total $^{1}$ & $\%$ & \\
\hline Controle & 4 & 1,33 & - \\
\hline Clastogenicidade & & & \\
Ab & $3^{\mathrm{a}}$ & 1,0 & - \\
\hline Anticlastogenicidade & & & - \\
Ara-C & $43^{3 *}$ & 14,33 & 25,6 \\
Ara-C + Ab & $33^{\mathrm{b}}$ & 11,0 & - \\
3DeoT & $39^{\mathrm{a}} *$ & 13,0 & 65,7 \\
3De0T $+\mathrm{Ab}$ & $16^{6 *}$ & 5,33 & \\
\hline
\end{tabular}

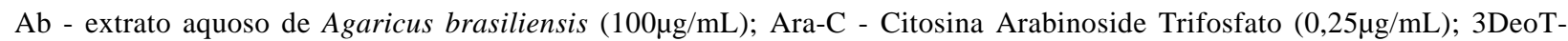
3'Deoxitimidina 5' Trifosfato $(0,5 \mu \mathrm{g} / \mathrm{mL}) ;{ }^{1}$ Número médio de células com aberrações cromossômicas em 300 células analisadas; ${ }^{a}$ Comparado ao Controle; ${ }^{\mathrm{b}}$ Comparado ao Ara-C; ${ }^{\mathrm{c}}$ Comparado ao 3DeoT; * Significativo.

Os dados da Tabela 4 mostram os tipos de aberrações cromossômicas encontradas. Observa-se que a maior parte das aberrações são do tipo cromatídica (quebras e rearranjos), assim como as da Tabela 2.

Tabela 4. Tipos de aberrações cromossômicas encontradas em culturas de CHO-k1 tratadas com inibidores de reparo de DNA e associadas ou não com Ab (AC-II).

\begin{tabular}{|c|c|c|c|c|c|c|c|c|c|c|}
\hline \multirow{3}{*}{ Tratamentos } & \multicolumn{10}{|c|}{ Número de aberrações cromossômicas } \\
\hline & \multicolumn{10}{|c|}{ Tipos de quebras } \\
\hline & ct & tr & $\mathbf{q r}$ & re & Total $^{1}$ & ic & $\mathbf{r}$ & dic & fa & Total $^{2}$ \\
\hline Controle & 3 & 0 & 0 & 0 & 3 & 0 & 0 & 0 & 1 & 1 \\
\hline \multicolumn{11}{|c|}{ Clastogenidade } \\
\hline $\mathbf{A b}$ & 2 & 0 & 0 & 1 & 3 & 0 & 0 & 0 & 0 & 0 \\
\hline \multicolumn{11}{|c|}{ Anticlastogenicidade } \\
\hline Ara-C & 38 & 0 & 0 & 0 & 38 & 4 & 0 & 0 & 1 & 5 \\
\hline $\mathbf{A r a C}+\mathbf{A b}$ & 42 & 0 & 0 & 0 & 42 & 8 & 0 & 0 & 0 & 8 \\
\hline 3DeoT & 42 & 1 & 1 & 4 & 48 & 7 & 0 & 0 & 0 & 7 \\
\hline 3DeoT+Ab & 14 & 1 & 0 & 0 & 15 & 2 & 1 & 0 & 0 & 3 \\
\hline
\end{tabular}

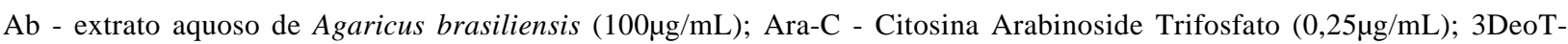
$3^{\text {'Deoxitimidina } 5}$ ' Trifosfato $(0,5 \mu \mathrm{g} / \mathrm{mL}) ;{ }^{1}$ Quebras do tipo cromatídicas: ct (quebra cromatídica), tr (trirradial), qr (quadrirradial), rc (rearranjo complexo); ${ }^{2}$ Quebras do tipo isocromatídicas: ic (quebra isocromatídica), $\mathrm{r}$ (anel), dic (dicêntrico), fa (fragmento acêntrico). 

quando associado aos inibidores de reparo de DNA, Ara-C e 3Deo T, in vitro.

\section{Ensaio do cometa}

A avaliação da genotoxicidade e/ou antigenotoxicidade do extrato aquoso de $\mathrm{Ab}$ foi realizada em células da linhagem CHO-k1, perante a inibição de reparo de DNA polimerase, pelo do ensaio do cometa.

A Tabela 5 mostra os resultados da genotoxicidade do extrato aquoso de $\mathrm{Ab}$, nas concentrações de 0,2, 0,4 e 0,6\%, bem como a antigenotoxicidade dos mesmos em associação com os inibidores Ara-C e 3DeoT. Verificou-se que a concentração de $0,2 \%$ não apresentou atividade genotóxica, pois não houve aumento significativo do número de células com dano, ao contrário das concentrações 0,4 e $0,6 \%$. Nos testes de antigenotoxicidade, verificou-se que o extrato de cogumelo, nas três concentrações testadas, quando associado aos inibidores Ara-C e 3DeoT, não apresentou atividade antigenotóxica, visto que, a redução do número de células com dano não foi significativa.

Tabela 5. Efeito genotóxico do extrato aquoso de Ab $10 \%$ na migração do DNA, associado ou não a inibidores de reparo de DNA.

\begin{tabular}{|c|c|c|c|c|c|c|}
\hline \multirow{3}{*}{ Tratamentos } & \multicolumn{6}{|c|}{ Número médio de células com cometa ${ }^{1}$} \\
\hline & \multirow{2}{*}{$\frac{\text { Total }}{\text { Média } \pm \text { DP }}$} & \multicolumn{4}{|c|}{ Classes } & \multirow{2}{*}{ Escores } \\
\hline & & $\mathbf{0}$ & 1 & 2 & 3 & \\
\hline Controle & $8 \pm 1,7$ & 92 & 8 & 0 & 0 & 8 \\
\hline EMS & $100^{\mathrm{a} *} \pm 0,0$ & 0 & 22,6 & 66,6 & 10,6 & 188 \\
\hline \multicolumn{7}{|l|}{ Genotoxicidade } \\
\hline Ab $0,2 \%$ & $6^{\mathrm{a}} \pm 2,6$ & 94 & 6 & 0 & 0 & 6 \\
\hline Ab $0,4 \%$ & $19,3 * \pm 3,0$ & 80,6 & 19,3 & 0 & 0 & 19,3 \\
\hline Ab 0,6\% & $39,6 * \pm 0,5$ & 60,3 & 39,6 & 0 & 0 & 39,6 \\
\hline \multicolumn{7}{|l|}{ Antigenotoxicidade } \\
\hline Ara-C & $99,4^{\mathrm{a} *} \pm 0,5$ & 0,6 & 65 & 28 & 6,3 & 140 \\
\hline Ara-C $+\mathrm{Ab}(0,2 \%)$ & $100^{\mathrm{b}} \pm 0,0$ & 0 & 74,3 & 23,3 & 2,3 & 128 \\
\hline Ara-C + Ab $(0,4 \%)$ & $100^{\mathrm{b}} \pm 0,0$ & 0 & 72,6 & 24,6 & 2,6 & 130 \\
\hline $\operatorname{Ara}-\mathrm{C}+\mathrm{Ab}(0,6 \%)$ & $90,4^{\mathrm{b}} \pm 8,3$ & 9,6 & 71,3 & 17,6 & 1,3 & 110,6 \\
\hline 3DeoT & $99^{\mathrm{a}} * \pm 1,7$ & 1 & 74,3 & 22 & 2,6 & 126,3 \\
\hline 3DeoT + Ab (0,2\%) & $90^{\mathrm{c}} \pm 13,9$ & 10 & 61 & 25 & 4 & 123 \\
\hline 3 DeoT + Ab $(0,4 \%)$ & $87^{\mathrm{c}} \pm 11,3$ & 13 & 75,6 & 11 & 0,3 & 98,6 \\
\hline 3 DeoT + Ab $(0,6 \%)$ & $88,7^{\mathrm{c}} \pm 13,0$ & 11,3 & 75 & 13 & 0,6 & 103 \\
\hline
\end{tabular}

Ab - extrato aquoso de Agaricus brasiliensis; EMS - etilmetanosulfonato $(155 \mu \mathrm{g} / \mathrm{mL})$; Ara-C - Citosina Arabinoside Trifosfato $(0,125 \mu \mathrm{g} / \mathrm{mL})$; 3DeoT- 3'Deoxitimidina 5' Trifosfato $(0,25 \mu \mathrm{g} / \mathrm{mL}) ;{ }^{1}$ Número médio de células com cometa, em 300 células analisadas, DP - Desvio Padrão. ${ }^{\mathrm{a}}$ Comparado ao Controle; ${ }^{\mathrm{b}}$ Comparado ao Ara-C; ${ }^{\mathrm{c}}$ Comparado ao 3DeoT; * Significativo.

\section{Discussão}

A composição química de Ab e suas atividades biológicas têm sido alvo de muitos estudos, devido ao seu uso na medicina popular para tratamento de diversas doenças, incluindo o câncer. Deve-se considerar que variações climáticas, geográficas e intra-específicas podem interferir na resposta biológica, assim como métodos de colheita e conservação dos cogumelos, podem promover perda ou degradação de compostos ativos (CHANG, 1996).

Trabalhos realizados por Menoli et al. (2001), Oliveira et al. (2002), Luiz et al. (2003b), Bellini et al. (2003) e Machado et al. (2005) demonstraram o efeito antimutagênico de extratos de $\mathrm{Ab}$, quando associado a agentes alquilantes indutores de dano no DNA, em testes in vitro, assim como Delmanto et al. (2001), em testes in vivo, associado a 
ciclofosfamida. Entretanto, outros estudos com extratos de $\mathrm{Ab}$, não mostraram atividade antigenotóxica e antimutagênica (GUTERREZetal., 2004; LUIZ et al., 2003a).

Vários estudos procuram compreender o mecanismo de ação de Ab, no reparo de DNA. Estudos como o de Oliveira et al. (2002), mostraram o efeito protetor de $\mathrm{Ab}$ nos tratamentos simultâneo (com MMS) e simultâneo com préincubação de extratos aquosos, no ensaio do micronúcleo em células V79, in vitro. Baseado na definição de Kuroda et al. (1992) sobre os mecanismos de antimutagênese, esses dados sugerem que os extratos apresentam atividade desmutagênica, ou seja, inativação química ou enzimática da substância mutagênica. Outros trabalhos também mostraram o potencial desmutagênico de $\mathrm{Ab}$, como os de Menoli et al. (2001) em tratamento simultâneo no ensaio do micronúcleo em células V79.

O Ab pode apresentar, ainda, atividade bioantimutagênica. Ele atua sobre os processos de mutagênese ou no sistema de reparo de DNA danificado e leva à redução da freqüência de mutações (KURODA et al., 1992), nas condições de pré e pós-tratamento no ensaio do micronúcleo, segundo os resultados obtidos por Oliveira et al. (2002) e por Luiz et al. (2003b), no teste de aberração cromossômica.

Foi observado também por Luiz et al. (2003b) a ausência de atividade anticlastogênica de extratos orgânicos de $\mathrm{Ab}$, em células deficientes em sistema de reparo (CHO-xrs5), sugerindo que esses extratos possuam substâncias que podem modular a atividade de reparo e replicação do DNA, atuando em nível celular por (i) aumentar a fidelidade na replicação do DNA; (ii) estimular sistema de reparo livre de dano; (iii) inibir o reparo propenso a erro.

Neste trabalho, o extrato aquoso de $\mathrm{Ab}$ apresentou atividade clastogênica na concentração de $0,6 \%$, e atividade genotóxica nas concentrações de 0,4 e $0,6 \%$, mostrando indução de danos nos tratamentos com altas concentrações do extrato. A concentração $0,4 \%$ mostrou-se indutora de danos pelo ensaio do cometa, já que este teste é mais sensível que o de aberração cromossômica.

Quanto a anticlastogenicidade, este extrato, na grande maioria dos tratamentos, não mostrou atividade protetora quando associada ao Ara-C e ao Ara-C + MMS, entretanto, quando associada ao 3DeoT, mostrou-se eficiente na redução de danos no DNA. Essa diferença entre a proteção do Ab contra os danos causados pela 3DeoT e a ausência de proteção quando associado ao Ara-C e Ara-C + MMS, deve-se ao fato de que esses inibidores atuam de maneira diferente: a Ara-C atua sobre a polimerase $\alpha$ (envolvida na iniciação da replicação) e a 3 DeoT sobre a polimerase $\beta$ envolvida no reparo do DNA nuclear danificado) (LEWIN, 2001). A Ara-C é um 2'desoxirribosídeo que é metabolizada até sua forma ativa Ara-CTP (ara-citidina monofosfato), que é um nucleotídeo inibidor competitivo da DNA polimerase $\alpha$ em relação ao substrato normal 2'-desocitidina fosfato (dCTP). Quando incorporada ao DNA, a Ara-C é capaz de inibir a síntese desta molécula, alterando a fita molde, impedindo a elongação da cadeia e a ligação de fragmentos de DNA recém sintetizados (SILVA; ERDTMANN; HENRIQUES, 2003). Já a 3DeoT atua no reparo do DNA que foi anteriormente sintetizado. Logo, sugerimos que os danos causados pela 3 DeoT sejam mais facilmente reparados quando associado a um produto antimutagênico, que quando associado a Ara-C.

Em relação à antigenotoxicidade, o extrato não apresentou atividade protetora quando associado a Ara-C e 3DeoT, pois não houve diminuição significativa do número de células com dano, porém não potencializou a atividade indutora de danos dos inibidores. Em vista disso, sugerimos que o ensaio do cometa não se mostra o mais adequado para avaliar 

quando associado aos inibidores de reparo de DNA, Ara-C e 3Deo T, in vitro.

antigenotoxicidade, pois é altamente sensível para indução de danos no DNA.

Vale ressaltar, ainda, que os resultados aqui obtidos do Ab com o inibidor de reparo 3DeoT, sendo protetor contra danos clastogênicos e não protetor contra danos genotóxicos, deve-se ao tipo de ensaio empregado. O teste de aberração cromossômica é empregado para verificar danos no DNA do tipo clastogênico (quebras no DNA, tanto cromatídicas como cromossômicas), enquanto que, o ensaio do cometa é utilizado para verificar lesões genômicas, que após serem processadas, podem vir resultar em mutações. (RIBEIRO; SALVADORI; MARQUES, 2003). Com isso, podemos dizer que o ensaio do cometa é bastante sensível, mais que o teste de aberração cromossômica.

Com base nos resultados obtidos no presente estudo, sugerimos cuidado na ingestão do chá de Ab em altas concentrações, devido a sua atividade genotóxica e clastogênica.

\section{Referências}

BELLINI, M. F.; GIACOMINI, N. L.; EIRA, A. F.; RIBEIRO, L. R.; MANTOVANI, M. S. Anticlastogenic effect of aqueous extracts of Agaricus blazei on CHO-k1 cells, studying different developmental phases of the mushroom. Toxicology in vitro, Oxford, v.17, n.4, p.465-469, 2003.

CHANG, R. Functional properties of edible mushrooms. Nutrition Review, New York, v.54, n.11, p.S91-S93, 1996.

DELMANTO, R. D.; LIMA, P. L. A.; SUGUI, M. M.; EIRA, A. F.; SALVADORI, D. M. F.; SPEIT, G.; RIBEIRO, L. R. Antimutagenic effect of Agaricus blazei Murrill mushroom on the genotoxicity induced by cyclophosphamide. Mutation Research, Amsterdam, v.496, n.1/2, p.1521, 2001.
EBINA, T.; FUJIMIYA, Y. Antitumor effect of a peptide-ucan preparation extracted from Agaricus blazei in a double-grafted tumor system in mice. Biotherapy, Dordrecht, v.11, n.4, p.259-265, 1998.

FUJIMIYA, Y.; SUSUKI, H.; KATAKURA, R.; EBINA, T. Tumor-specific cytotoxicity and immunopotentiating effects of relatively low molecular weight products derived from the basidimycete, Agaricus blazei Murrill. Anticancer Research, Atenas, v.19, n.1A, p.113-118, 1999.

GUTERREZ,Z. R.; MANTOVANI, M. S.; EIRA, A. F.; RIBEIRO, L. R.; JORDÃO, B. Q. Variation of the antimutagenicity effects of water extracts of Agaricus blazei Murrill in vitro. Toxicology in vitro, Oxford, v.18, n.3, p.301-309, 2004.

ITO, Y.; NAKAMURA, Y. Supression of aflatoxin B 1 or methylmethanesulfonate-induced chromosome aberrations in rat bone marrow cells after treatment with S-methyl methanesulfonate. Mutation Research, Amsterdam, v.393, p.307-316, 1997.

ITOH, H.; AMANO, H.; NODA, H. Inhibitory action of a (1-6) $\beta$-glucan-protein complex (FIII$2 b)$ isolated from Agaricus blazei Murrill ("Himematsutake") on meth a fibrosarcoma bearing mice and its antitumor mechanism. Japanese Journal of Pharmacology, Kyoto, v.66, p.265-271, 1994.

KAWAGISHI, H.; INAGAKI, R.; KANAO, T.; SHIMURA, K.; ITO, H.; HAGIWARA, T.; NAKAMURA, T. Fraction and antitumor activity of the water-insoluble residue of Agaricus blazei fruiting bodies. Carbohydrate Research, Amsterdam, v.186, p.267-273, 1989.

KAWAGISHI, H.; KANAO, T.; INAGAKI, R.; MIZUNO, R.; SHIMURA, K.; ITO, H.; HAGIWARA, T.; NAKAMURA, T. Formolysis of a potent antitumor (1-6) $\beta$-D-glucan-protein complex from Agaricus blazei fruiting bodies and antitumor activity of the resulting products. 
Carbohydrate Polymers, Barking, v.12, p.393-403, 1990.

KOBAYASHI, H.; SUGIYAMA, C.; MORIKAWA, Y.; HAYASHI, M.; SOFUNI, T. A comparison between manual microscopic analysis and computerized image analysis in the single cell gel electrophoresis assay. MMS Commun., v. 3, p. 103-115, 1995.

KURODA, Y.; JAIN, A. K.; TEZUKA, H.; KADA, T. Antimutagenicity in cultured mammalian cells. Mutation Research, Amsterdam, v.267, p.201209, 1992.

LEWIN, B. Genes VII. Porto Alegre: Ed. Artmed, 2001.

LUIZ, R. C.; JORDÃO, B. Q.; EIRA, A. F.; RIBEIRO, L. R.; MANTOVANI, M. S. Nonmutagenic or genotoxic effects of medicinal aqueous extracts from de Agaricus blazei mushroom in V79 cells. Cytologia, Tokyo, v.68, p.1-6, 2003a.

LUIZ, R. C.; JORDÃO, B .Q.; EIRA, A. F.; RIBEIRO, L. R.; MANTOVANI, M. S. Mechanism of anticlastogenicity of Agaricus blazei Murrill mushroom organic extracts in wild type $\mathrm{CHO}$ (k1) and repair deficient (xrs5) cells by chromosome aberration and sister chromatid exchanges assays. Mutation Research, Amsterdam, v.528, p.75-79, 2003b..

MACHADO, M. P.; RODRIGUES, E.; TEREZAN, A. P.; RIBEIRO, L. R. MANTOVANI, M. S. Cytotoxicity, genotoxicity and antimutagenicity of hexane extracts of Agaricus blazei determined in vitro by the comet assay and $\mathrm{CHO} / \mathrm{HGPRT}$ gene mutation assay. Toxicology in vitro, Oxford, v.19, p.533 - 539, 2005.

MENOLI, R. C. R. N.; MANTOVANI, M. S.; RIBEIRO, L. R.; SPEIT, G.; JORDÃO, B. Q. Antimutagenic effects of the mushroom Agaricus blazei Murrill extracts on V79 cells. Mutation Research, Amsterdam, v.496, p.5-13, 2001.

MIZUNO, T. Bioactive biomolecules of mushrooms: food, function and medicinal effect of mushroom fungi. Food Review International, New, York, v.11, n.1, p.7-21, 1995.

OLIVEIRA, J. M.; JORDÃO, B. Q.; RIBEIRO, L. R.; EIRA, A. F.; MANTOVANI, M. S. Antigenotoxic effect of aqueous extracts of sun mushroom (Agaricus blazei Murill lineage 99/26) in mammalian cells in vitro. Food and Chemical Toxicology, Oxford, v.40, p.1775-1780, 2002.

RIBEIRO, L. R.; SALVADORI, D. M. F.; MARQUES, E. K. Mutagênese ambiental. Canoas: Ed. Ulbra, 2003.

SILVA, J.; ERDTMANN, B.; HENRIQUES, J. A. P. Genética Toxicológica. Porto Alegre: Ed. Alcance, 2003.

SPEIT, G.; HARTMANN, A. The Comet Assay (Single-Cell Gel Test), a Sensitive Genotoxicity Test for detection of DNA damage and repair. In: HENDERSON, D. S. Methods in Molecular Biology: DNA Repair in Protocols - Eukaryotic Systems. Totowa: Humana Press, 1999. v.113, p.203-211.

WASSER, S. P.; DIDUKH, M. Y; AMAZONAS, M. A. L. A.; NEVO, E.; STAMETS, P.; EIRA, A. F. Is a widely cultivated culinary-medicinal royal sun Agaricus (the Himematsutake mushroom) indeed Agaricus blazei Murrill?. International Journal Medical, Mushroom, v.4, p.267-290, 2002.. 